\title{
Livros literários em sala de aula: possibilidades de leitura e conversa literária
}

\author{
Literary books in the classroom: possibilities in reading and \\ literary conversation
}

\section{Rosa Maria Hessel Silveira}

Universidade Federal do Rio Grande do Sul - UFRGS - Porto Alegre - Rio Grande do Sul - Brasil

\section{Letícia Fonseca Richthofen de Freitas}

Universidade Federal de Pelotas - UFPEL - Pelotas - Rio Grande do Sul - Brasil

Resumo: O artigo objetiva analisar a recepção de três obras dos acervos para anos iniciais do Programa Nacional Biblioteca na Escola (PNBE) 2012, com a finalidade de contribuir para a reflexão sobre possíveis práticas de leitura literária em anos iniciais. A análise foi feita no material gerado em sessões de leitura de tais livros em três escolas públicas do Rio Grande do Sul, abordando os seguintes tópicos: as possibilidades de enriquecimento da leitura compartilhada, quando feita de forma interativa em sala de aula; a importância de uma leitura multissemiótica (multimodal) dos livros; a importância de uma articulação entre o universo ficcional da obra e as experiências pessoais, culturais e sociais das crianças; a produtividade de instrumentalizar o aluno para manipular elementos paratextuais do objeto livro.

Palavras-chave: Literatura Infantil. Leitura literária. Sala de aula.

Abstract: This paper aims to analyze the reaction to three books that belong to the collection for the early years of elementary school developed by the 2012Library at School National Program (Programa Nacional Biblioteca na Escola - PNBE). It has the intention of contributing to the reflection of possible practices of literary reading in the early years. This analysis was based on the material that resulted from reading sessions of these books at three public schools in Rio Grande do Sul - Brazil, and it addresses the following topics: possibilities for enriching shared reading in class when done interactively; the significance of multi-semiotic (multimodal) reading of children's literature; the importance of articulating the book's fictional universe with the children's personal, social and cultural experiences; the usefulness of helping students to use paratextual elements of the targeted book.

Keywords: Literature for children. Literary Reading. Classroom. 


\section{Contextualizando o estudo}

A leitura na escola parece constituir um tema inesgotável e sempre atual nas discussões da arena pedagógica, frequentemente ultrapassando tal âmbito e repercutindo na mídia, por exemplo. Ao mesmo tempo em que algumas assertivas aparecem como inquestionáveis (ou quase) em tais discussões, como a que enfatiza a importância da escola no desenvolvimento das práticas leitoras, outras são objeto de disputas (teóricas e/ou metodológicas), apontando para controvérsias sobre o que se entende por leitura, por objetos legítimos de leitura, sobre o lugar da leitura literária ou, mesmo, sobre a efetiva importância dos novos suportes de língua escrita que estão ganhando extraordinário espaço neste milênio. É dentro desse campo mais geral de discussões e de problematizações que se situa o presente trabalho, o qual, a partir de dados empíricos em diálogo com contribuições teóricas, procura contribuir para o equacionamento das possibilidades de abordagem de livros literários em sala de aula nos anos iniciais do ensino fundamental.

Decorre o presente artigo de pesquisa intitulada Literatura infantil - um estudo sobre leituras de obras selecionadas com leitores de anos iniciais ${ }^{1}$, cujo objetivo principal foi analisar a recepção, por grupos de alunos de anos iniciais de escolas públicas do Rio Grande do Sul, de um conjunto de obras com temáticas e gêneros diferenciados, escolhidas da listagem de livros divulgada pelo programa governamental de âmbito federal PNBE (Programa Nacional Biblioteca na Escola), que, de 1997 até 2015, constituiu anualmente acervos de livros para diferentes níveis de escolaridade e os distribuiu para todas as escolas públicas brasileiras.

Uma breve notícia sobre o citado programa (PAIVA, 2012a) nos informa que, no período de 2006

\footnotetext{
O referido projeto contava com pesquisadores de três universidades distintas (UFRGS, ULBRA e UFPel), tendo sido realizado com 0 apoio do Conselho Nacional de Desenvolvimento Científico e Tecnológico (CNPq), através de Bolsa PQ e IC. Foi aprovado pelo Comitê de Ética da Universidade Federal do Rio Grande do Sul, em 2013, tendo sido, portanto, obedecidos todos os procedimentos éticos estabelecidos para pesquisa.
}

a 2012, foi distribuído às bibliotecas das escolas públicas brasileiras um número superior a 14 milhões de volumes que tinham como destinatário alunos do Ensino Fundamental do $1^{\circ}$ ao $5^{\circ}$ ano. É necessário registrar também que a constituição desses acervos se fez através de análise empreendida por equipe nacional de especialistas em literatura infantil, atendidos os critérios de qualidade do projeto gráficoeditorial e qualidade do texto, além da adequação à faixa etária pretendida.

Se grande foi 0 esforço governamental brasileiro em dotar as escolas públicas de acervos de livros com qualidade (esforço bastante reconhecido no campo acadêmico), nem sempre, entretanto, tem se verificado um efetivo trabalho da equipe escolar (supervisão, bibliotecários, professores) com tais livros, os quais, com alguma frequência, são ignorados e/ou subutilizados pelos professores, por motivos muito diversos. Nesse sentido, a partir da constatação de uma efetiva escassez de estudos que se debruçassem sobre a articulação entre tais acervos e o seu público alvo, foi delineada a pesquisa da qual deriva o presente estudo. Seu desenho investigativo envolveu a escolha de algumas das obras constantes dos acervos já distribuídos - no caso específico, dos acervos para anos iniciais do PNBE $2012^{2}$-, selecionadas por pertencerem a gêneros distintos e abordarem temáticas também diversas, assim como o estudo de sua recepção, entendida como o conjunto de negociações entre experiências, vivências, conhecimentos e expectativas, por um lado, e o objeto livro (com os textos que abriga), por outro, por parte de leitores dos anos iniciais de escolas públicas.

Procedemos, pois, à realização de sequências de encontros em sala de aula, com as turmas completas $^{3}$, nos quais foi realizada uma exploração de seis títulos diferentes - três deles analisados aqui do acervo, em cada uma das três escolas

\footnotetext{
2 O PNBE 2012 foi a última edição do Programa que distribuiu acervos para os anos iniciais. Em 2018, o MEC anunciou uma substituição do PNBE pelo PNLD literário, com características diversas.

${ }^{3}$ O número total de alunos foi de 66, assim distribuídos: 19 na primeira escola, 20 na segunda e 27 na terceira.
} 
pesquisadas ${ }^{4}$. Em tais encontros, cada aluno tinha acesso a um exemplar da obra que estava sendo lida e discutida em conjunto. Ressalta-se a importância da mediação realizada nas referidas sessões, uma vez que cada encontro contava sempre com a presença de dois pesquisadores da equipe que conduziam a leitura conjunta e a discussão das obras escolhidas, seguida de atividades elaboradas pela equipe e aplicadas com a colaboração das professoras das turmas e de estagiárias ${ }^{5}$. Todas as sessões foram filmadas e trabalhos posteriores variados foram produzidos pelas crianças; a análise das sessões filmadas, dos trabalhos produzidos e das anotações do diário de campo dos pesquisadores propiciaram o levantamento de alguns tópicos a serem discutidos e analisados, em confronto com outras pesquisas do campo da leitura e da literatura infantil.

Vários tópicos de interesse para uma educação literária emergiram das análises realizadas na pesquisa, mas neste trabalho específico situamos os seguintes: 1 . as possibilidades de produtividade da leitura compartilhada e de sua discussão (conversa literária), quando realizada em sala de aula, desde que com uma mediação adequada pelo(a) professor(a); 2. a importância de uma leitura multissemiótica (multimodal) de livros de literatura infantil, considerando a relevância da imagem e do projeto gráfico em tais obras e a possibilidade de 0 professor ser um mediador que leve o aluno a desenvolver sua competência em apreciar e aprofundar as relações entre texto e imagem; 3. a importância de se propiciar uma articulação entre o universo ficcional construído pelo livro com as experiências pessoais, culturais e sociais das crianças, e 4. a possibilidade e a fecundidade de instrumentalizar o aluno para atentar e para manipular elementos do objeto livro: autor, ilustrador, tradutor, contracapa, edição e outros elementos paratextuais (biografias, dedicatórias etc.), não com um intuito formal, conteudístico, mas como veículos de

\footnotetext{
${ }^{4}$ Duas das escolas pesquisadas situam-se no município de Porto Alegre (RS) e a terceira no município de Pelotas (RS).

${ }^{5}$ Por motivo de sigilo, tanto as escolas, incluindo-se aí a equipe diretiva, a coordenação pedagógica e as professoras das turmas, não serão aqui nomeadas.
}

informações que podem enriquecer a própria leitura do texto principal.

Ressaltamos que tais tópicos não são trazidos aqui como conclusões acabadas, mas como itens a serem considerados para a potencialização de práticas enriquecedoras de obras de literatura por crianças de escolas públicas. Alguns limites e dificuldades a eles associados também podem ser identificados, como a questão da manutenção de interesse e organização do espaço de sala de aula frente à (im)possibilidade de exemplares de um mesmo título para todos os alunos, assim como a necessidade de um planejamento detalhado (incluindo a análise prévia do texto imagético) para a realização de tais sessões.

São esses resultados ou temas a discutir que passamos a expor, com algumas exemplificações.

\section{Aprendendo com as sessões de leitura}

Se antes aludimos a tópicos consensuais quando se discutem práticas de leitura no espaço escolar, é preciso recuperar um deles, qual seja, a importância do professor como mediador dos eventos de leitura. Tal importância, evidentemente, não radica na intervenção do professor no sentido de conduzir a leitura buscando um único entendimento para a obra lida (o que, tradicionalmente, se nomeava como "mensagem" do livro); pelo contrário, tais eventos se tornam significativos a partir de uma leitura compartilhada, aberta, que permita explorar múltiplos sentidos do livro (ROCHE, 2014). É nesta direção que uma das premissas que guiaram as sessões de leitura do referido projeto aponta para a busca conjunta de significados possibilitados pelo texto, numa leitura que se abra à interação entre os alunos e os pesquisadores. Nesse sentido, adotamos a posição de que

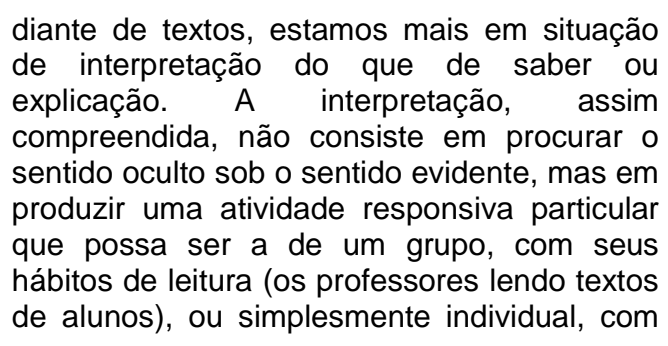

diante de textos, estamos mais em situação de interpretação do que de saber ou explicação. A interpretação, assim produzir uma atividade responsiva particular que possa ser a de um grupo, com seus de alunos), ou simplesmente individual, com 
outros critérios de julgamento (DELAMOTTELEGRAND, 2009, p. 21).

Ainda que, na reflexão acima mencionada, a autora não refira trocas de entendimentos de textos entre os leitores, sua observação se articula com nossa experiência de pesquisa. Assim, no que tange às práticas compartilhadas e interativas de leitura em sala de aula, sob coordenação de um(a) pesquisador(a), mas com a presença e colaboração da professora de classe, surpreendeu-nos, muitas vezes, a fecundidade dessas trocas entre os leitores. Roche (2014) chama a atenção para a necessidade de esse encontro possibilitar um ambiente propício para que a criança possa falar e ser ouvida, além de oportunizar uma conexão entre a vida do aluno e as vidas retratadas na obra. Colomer (2007), ao discorrer sobre pesquisas que investigaram práticas de leitura compartilhada, corrobora essa ideia e destaca a forma como, nas práticas compartilhadas de leitura, se propicia que as crianças busquem conjuntamente os significados, ao invés de somente inquirir sua compreensão ou reação individual.

Uma das vozes que mais têm encontrado repercussão na ênfase à importância das conversas sobre leituras literárias tem sido Aidan Chambers (2007a, 2007b, 2008), que, para além de outras abordagens relevantes, dedicou uma obra inteira à discussão tanto de aspectos produtivos como de traços prejudiciais ao que chama de "conversa literária", relembrando que "nuestra conversación sobre los libros, más que ninguna outra cosa, nos engrandece y nos profundiza como lectores" (2007b, p. 118).

É evidente que as conversas sobre leitura em sala de aula apenas se mostram profícuas se 0 mediador se mostrar sensível, atento e instigador às múltiplas dimensões da leitura, e abra um espaço para a manifestação de entendimentos, hipóteses, manifestações emotivas, confirmações, desmentidos e dúvidas. Nunca é demais lembrar que tais leituras fogem ao antigo padrão de perguntas e respostas em que o professor perguntava para saber se o aluno "tinha lido atentamente", "com correção" e se "tinha entendido o que o livro quis dizer" - práticas ainda hoje tão presentes em nossas salas de aula.

Traremos a seguir alguns recortes de conversas de sala de aula motivadas pelas leituras de alguns livros trabalhados. Iniciaremos com a conversa literária realizada a partir do livro Obax, de André Neves. Essa obra, lançada em 2010, recebeu importantes prêmios literários, no Brasil e na Itália, e narra a história de Obax, uma protagonista menina que vivia em um povoado da África. Já que o povoado em que ela vivia era pequeno e isolado e, nele, ela não tinha muitos amigos, sua brincadeira era inventar histórias, que as pessoas ouviam incrédulas. Na sequência do enredo, Obax contou que tinha visto cair do céu uma chuva de flores, o que provocou muitos risos de todos que a ouviam. Desapontada, a menina, ao tropeçar em uma pedra em forma de elefante, decide sair mundo afora, na companhia de Nafisa (o que se depreende ser um amigo imaginário, talvez "sugerido" pela pequena pedra), um elefante, a fim de encontrar uma chuva de flores. Depois de dar a volta ao mundo sem encontrar a chuva de flores, Obax retorna ao povoado e conta as aventuras por que passou na companhia de Nafisa. Novamente, ninguém acredita na menina, mas Obax quer provar que elas aconteceram, mostrando Nafisa, que representaria a prova de sua viagem. Quando todos saem da cabana onde se encontravam, em busca de Nafisa, a única coisa que encontram é a pequena pedra; a menina, então, triste, decide enterrá-la. No dia seguinte, os moradores do vilarejo percebem pássaros no céu e, para surpresa de todos, no lugar onde Obax tinha enterrado a pedra, havia nascido um imenso baobá, cuja copa estava cheia de flores. Ao se aproximar da árvore, os pássaros bateram as asas, e uma chuva de flores caiu. Desde então, afirma o narrador onisciente, todos passaram a prestar atenção nas histórias de Obax.

A síntese verbal que fizemos do enredo empobrece a leitura do livro, em que as narrativas verbal e imagética de André Neves se entrelaçam de forma original e produtiva. Um exemplo é o de que as imagens indicam - pela utilização de uma mesma textura da coloração da pedra, do elefante e do baobá 
- que os três "entes" são transformações de um mesmo ser ou partilham algo comum. Esta é uma leitura sugerida, mas não explicitada, constituindo uma das dimensões da literariedade da obra - e adiante veremos como as crianças das três turmas lidaram com tal "enigma". O grande tema da história de Obax parece ser efetivamente o poder da imaginação e da fantasia.

Muitas discussões foram ensejadas pela leitura conjunta do texto verbal e dos aspectos imagéticos do livro, numa discussão deflagrada tanto pela pesquisadora como pelos alunos. A referência de Obax, um nome estranho, considerando que, em Língua Portuguesa, oxítonas terminadas em -ax não são palavras frequentes, foi o primeiro enigma que se colocou e foi debatido. Alguns alunos, a partir das primeiras páginas que antecedem a narrativa, sugeriram que Obax era o pequeno seixo (a "bolinha") com que a protagonista brincava; outros sugeriram que se tratava de um menino (afinal, o nome próprio e a ilustração da capa permitiam uma leitura de ambos os gêneros), mas a continuidade do texto escrito dirimiu tal possibilidade. Vê-se assim como, nesse jogo de antecipações, permitido e incentivado pelo mediador, sucessivamente leituras possíveis vão sendo descartadas, quando o texto dá limites de interpretação, ou se abrindo, quando o texto a deixa em suspenso.

Mas certamente, nas três turmas trabalhadas, o tema mais discutido - porque deixado em aberto no texto escrito e apenas sugerido nas ilustrações - foi o da identificação do tipo de relação entre a pedrinha, o elefante e a árvore do desfecho da narrativa. Vejamos um recorte de uma das sessões, logo após o final da leitura conjunta 6 .

$P$ - Pois então, a história terminou, mas eu quero que vocês me interpretem essa história.

\footnotetext{
6 As transcrições seguiram as convenções ortográficas, desprezando-se questões de pronúncia coloquial, irrelevantes para o estudo, e normalizamos as indicações de plural, mas respeitando integralmente a escolha lexical e de construções. Utilizamos convencionalmente $\mathrm{P}$ para a voz da pesquisadora ou pesquisador que coordenava as sessões, A para a voz dos alunos, utilizando-se algarismos crescentes para diferenciá-los, e T quando a turma falava em conjunto.
}

Que difícil, né? Afinal, como é que era a Obax? Ela viu a chuva de flores? O que é que vocês... A1 - A pedra não era uma pedra.

$P$ - Ah, ele disse assim, "a pedra não era uma pedra", era o quê?

A1 - O elefante!

A2 - O elefante!

A3 - Uma árvore!

$P$ - Era uma árvore. Por que que tu acha que era uma árvore?

A3 - Por causa que (...)(Incompreensível)

$P$ [REPETINDO O QUE O ALUNO DISSE] Ah, ela plantou e nasceu uma árvore.

A4 - Era uma semente.

$P$ - Era uma semente, então.

A5 - Mas como ela andou no elefante?

$P-\tilde{A} h ?$

A5 - Como ela andou no elefante? Como ela andou no elefante?

P - Ah, boa pergunta. Ele pergunta: como ela andou no elefante? Ó, vamos ver lá, todo mundo tem o livro aqui, deixa eu ver, ó... Aqui na página 17, vocês viram que tem o numerozinho aqui embaixo... Mas não... aqui ela tá olhando uma...

A1 - Pedra.

A2 - Pedra.

$P$ - Pedra. E aqui ela está...

A1 - Em cima do elefante.

$P$ - Falando com o elefante.

A2 - Não tá em cima.

$P$ - Tem algumas semelhanças no elefante..

A1 - Aqui eu vi uma pedrinha do lado dela.

$\mathrm{P}$ - Ah, viu uma pedrinha do lado dela. Aqui ó, ele viu uma pedrinha do lado dela. Mas afinal o que que tem a ver a pedra, o elefante e a árvore?

P - Primeiro, vamos, primeiro. Pode falar, vamos.

A1 - O elefante tem os mesmos desenhos e a mesma cor da árvore que nasceu.

$P$ - Tá, o elefante tem os mesmos desenhos e a mesma cor da árvore que nasceu. Quem mais tem uma ideia?

$\mathrm{P}$ - $\mathrm{O}$ que que tem a ver a pedra com $\mathrm{O}$ elefante?

A2 - A pedra parece com isso aqui ó. [MOSTRA A TEXTURA COMUM AOS 3 SERES]

$\mathrm{P}$ - A pedra o quê?

A2 - Ela parece com isso aqui.

P - Parece...

A1 - O elefante pode ter se transformado na pedra.

$P$ - Ah, o elefante pode ter se transformado na pedra ou...

A2 - Ou ela ter imaginado.

$P$ - Ela também poderia ter imaginado. E por que que será que ela poderia ter imaginado? Porque aqui ó ela tá na vila, aí ela tá ainda... ela tá viajando. Aí ela volta e diz "vamos lá fora. Eu vou provar que eu fiz tudo isso." E daí ela pensa, "lá fora tá o meu elefante". E aí ela sai lá fora e o que que acontece?

A1 - Ele tá pequeno igual antes (...) 
P - A pedrinha e o buraco, é um buraco no chão?

A2 - A pedrinha que é o elefante.

$P$ - Então pode ser que ela... que ela imaginou ou não?

A1 - Sim.

A2 - Ou imaginou que a pedra era o elefante grande.

$\mathrm{P}$ - Ó, uma ideia! O que que vocês acham da ideia da colega?

A2 - Ela imaginou que a pedra pudesse ser o elefante.

É nesta fervilhante conversa, em que sugestões são levantadas, descartadas ou partilhadas - enquanto os alunos folheiam as páginas na busca das pistas sugeridas pelos colegas ou das suas próprias hipóteses, que a troca de interpretações se faz potente, numa resposta à situação da conversa literária motivada por uma obra de qualidade, em que palavra e imagem se entrelaçam de forma sugestiva e nada óbvia.

Trazemos a seguir também alguns recortes da experiência de conversa realizada a partir do livro $A$ Grande Fábrica de Palavras, de Agnès de Lestrade, com ilustrações de Valeria Docampo, que poderia ser considerado uma espécie de obra de fantasia moderna, conforme a categorização de COLOMER (2003). Para a autora,

O desenvolvimento da fantasia moderna supôs a criação de novos imaginários de ficção a partir de diversos caminhos, associados majoritariamente ao humor: a alteração da vida cotidiana dos personagens ao irromperem elementos fantásticos, a exploração especulativa sobre o funcionamento ou consequências de fenômenos e mundos possíveis, a desmitificação dos elementos fantásticos tradicionais e o jogo metaliterário sobre as regras da construção narrativas (COLOMER, 2003, p. 223).

No caso do livro em questão, não temos especificamente o aproveitamento do humor, mas a proposição de um mundo "possível" que, guardando relações com o mundo real, possibilita, por sua arquitetura narrativa, uma reflexão sobre o mesmo. A história narrada se passa em um país onde se fala muito pouco, pois as palavras custam caro. Lá existe "a grande fábrica de palavras", e é preciso comprá-las e engoli-las para depois falar. Assim, quem possui muito dinheiro, pode comprar palavras caras e falar o que quiser, mas quem não o tem muitas vezes procura palavras sem muito valor no lixo ou recolheas ao vento. Pela leitura, ficamos sabendo que Philéas, o menino que protagoniza a história, é apaixonado por Cybelle e gostaria de dizer a ela palavras bonitas e caras, como, por exemplo, "eu te amo". Seu rival, Oscar, é muito rico, tem inúmeras palavras a seu dispor e diz a Cybelle que a ama e que um dia vai se casar com ela, para desespero de Philéas, que só pode pronunciar, para sua amada, as três palavras que conseguiu recolher ao vento: "poeira, cereja e cadeira". Como também não pode falar, Cybelle sorri e dá um beijo em Philéas, se comunicando com ele de outra maneira que não a verbal.

O livro - especialmente fecundo quanto a sugestões de interpretação, pelo seu caráter simbólico - possibilitou muitas discussões e ilações durante a leitura. Um dos primeiros aspectos que merecem destaque diz respeito à rápida inferência feita pelas crianças - com base em uma ilustração que mostra uma mulher remexendo uma grande lata de lixo e catando palavras - de que no país da fábrica de palavras só quem tem dinheiro pode comprar palavras:

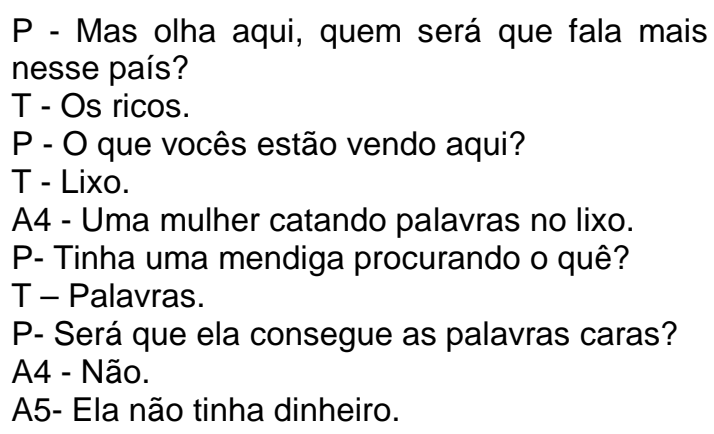

Uma percepção bastante parecida tiveram as crianças de outra das escolas pesquisadas para esta mesma passagem do livro:

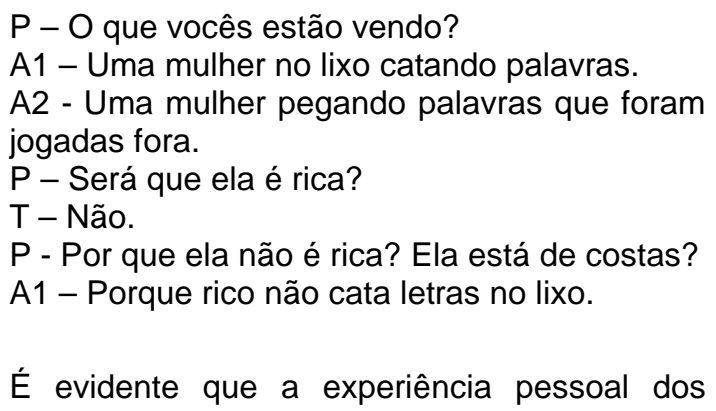
alunos tem seu papel nesta leitura de uma ficção 
fantástica que, para além da situação imaginativa, repousa sobre aspectos fatuais muito palpáveis para eles - a distinção social entre "pobres" e "ricos", distinção, aliás, presente na literatura infantil desde seu surgimento, com a apropriação dos Contos de Fadas. Além disso, a partir da conversa sobre a leitura, discutiu-se o fato de as ilustrações mostrarem que as pessoas mais ricas usavam roupas que continham palavras e textos escritos, enquanto 0 vestuário das pessoas mais pobres equivalia a folhas de caderno em branco, só com linhas, sem texto, ou com desenhos, não havendo nada escrito. A partir da relação imagem e texto, as crianças levantaram hipóteses sobre como se vestiriam e se comportariam as pessoas ricas, em contraposição às pessoas pobres:

$P$ - $O$ que que tem nessa imagem?

A6 - Roupas com palavras.

A7 - Uma bolsa cheia de palavras.

$\mathrm{P}$ - O que que tu estás vendo?

A8 - Aqui tem uma loja escrito "palavras de verão".

A9 - Tem dois homens sentados, comendo.

$P$ - Eles estão comendo em um restaurante chique, com um prato cheio de palavras.

Então, o que tu estás vendo?

A6 - Ela tá com uma bolsa cheia de palavras.

$P$ - Parece o quê? Será que ela é pobre?

A6 - Não, rica.

$P-E$ a roupa desse homem, o que parece?

A7 - A dos presos americanos.

$P$ - Mas não lembra nada que vocês conhecem?

A8 - Papel.

$P$ - Isso, papel.

A7 - De caderno.

$P$ - E está escrito nela?

T - Não.

Ainda que ambos os excertos sejam apenas um pálido reflexo do turbilhão de intervenções dos alunos, que irrompiam em sala de aula quando eram desafiados por uma obra com qualidades literárias e imagéticas e por uma situação de abertura à discussão e interação, os recortes citados ilustram o que, pois, entendemos como primeiro pressuposto de nossa discussão: a fecundidade de uma leitura compartilhada em sala de aula, desde que com uma mediação adequada pelo/a professor/a. Ainda com relação à leitura dessa obra, é interessante exemplificar outro episódio em que uma criança, desafiada pelo problema narrativo colocado - em um país onde as palavras devem ser compradas, como se vai falar? - levanta uma hipótese de solução: "Eu iria escrever as palavras e iria comer...”. Entretanto, outro colega rebate: "Será que (não) tem papel? Só na fábrica?".

Para além do trabalho com $A$ grande fábrica de palavras, outros muitos exemplos poderiam ser retirados do nosso corpus. Fixamo-nos a seguir em alguns diálogos que surgiram quando da leitura de outro livro do acervo do PNBE, Controle Remoto, de Tino Freitas e ilustrações de Mariana Massarani. A obra foi considerada "altamente recomendável para crianças" na avaliação da Fundação Nacional do Livro Infantil e Juvenil no ano de 2011; também foi selecionada para a lista dos 30 melhores livros infantis do ano da Revista CRESCER, em 2011, e para o Catálogo de Bologna, em 2010. Além disso, ficou em 3ำ Lugar no Prêmio Glória Pondé 2010 (Melhor livro infantil).

Escrito em tom jocoso e lúdico, o livro apresenta a história de um bebê que é entregue pela cegonha, junto com um controle remoto, dentro de uma cesta. Passados alguns meses, pai e mãe descobrem que o controle remoto funciona para comandar o bebê através da função de suas teclas: play (brincar), sleep (dormir), stop (parar tudo), alarm (hora de acordar), mute (silêncio total), repeat (faça o que digo). Temos, novamente, um exemplo de livro que propõe uma situação fantástica, para explorar metaforicamente uma circunstância da nossa experiência, mas agora (se compararmos com o livro anterior) com um acento contemporâneo - a falta de tempo dos adultos para com as crianças, motivada em parte pelo seu envolvimento com os aparelhos eletrônicos. No caso desta obra, o humor - presente tanto no texto escrito quanto nas ilustrações desempenha importante função.

Pois bem: muitas situações se sucedem na trama, até o dia em que a carga das pilhas do aparelho termina. Substituídas as pilhas, entretanto, o menino vem a apresentar a síndrome da "controlerremotite aguda", causada, segundo o técnico consultado, pelo uso abusivo do aparelho. 
Com a recomendação de jogar o controle remoto fora e passar a ouvir o menino e suas vontades, uma nova relação se estabelece entre os pais e o filho e sobrevém um final pacificador - resolvendo-se 0 conflito narrativo.

A novidade do projeto gráfico do livro, cujo formato retangular vertical lembra um controle remoto, e que utiliza em praticamente todas as suas páginas, palavras (comandos) e ícones encontrados nesses aparelhos, oferece um grande potencial de exploração de leitura com os pequenos habitantes desse mundo dos aparelhos eletrônicos, os quais, desafiados, respondendo e ouvindo respostas de colegas, já se situam em relação à proposta editorial global da obra. Numa das turmas, já com o livro nas mãos, mas antes de abri-lo, desencadeou-se o seguinte jogo de antecipações:

P- Muito bem, vamos começar. Seguinte, vou perguntar para vocês o que este livro lembra, quando a gente pega ele assim?

A1 - Controle remoto.

$\mathrm{P}$ - Ah é? Por quê?

A1 - Porque o título é "controle remoto".

A2 - Porque tem uma TV.

A3 - Tem uma mãozinha que está com o controle remoto aqui.

A4 - O cara está assistindo TV com dois controles remotos! (referindo-se a uma das imagens da capa em que o pai é visto sentado frente à TV manejando o controle remoto desta e o do filho)

Outra pequena passagem também é reveladora da leitura engajada realizada pelas crianças. Assim, um aluno, por exemplo, comenta, após a provocação da pesquisadora:

P - Como era para os pais terem o controle remoto?

A10 - Muito fácil, porque o menino bagunçava muito e eles tinham muito trabalho, eles só botavam no canal de desenhos animados, botavam ele no sofá e botavam pause.
A11 - O menino não fazia o que ele queria, ele só fazia o que os pais mandavam.

A12 - Eles até poderiam colocar o filho para trabalhar.

A14 - Isso seria crime, daí eles são presos.

É interessante observar como, em suas trocas, os alunos expandem as possibilidades de aplicação de uma hipótese do mundo ficcional - a do controle total da criança pelos pais - e aludem à possibilidade de isso ser usado para "colocar o filho para trabalhar". Entretanto, rapidamente um aluno relembra a máxima legal, que circula amplamente pela mídia brasileira, de que "trabalho infantil é crime", com a inferência imediata de que os pais poderiam então ser presos, articulando a possibilidade ao quadro de seus conhecimentos prévios.

Também no caso de Controle Remoto, a própria presença de controles remotos nas casas das crianças, assim como a questão da língua em que os comandos do controle são identificados (Inglês), resultou em observações e comentários em que os alunos articulavam suas experiências com passagens da obra, de maneira ora mais ora menos provocada pela pesquisadora. No caso do neologismo controlerremotite aguda (correspondente ao diagnóstico que um técnico fez do menino e que corresponderia a um excesso de uso do controle remoto), foi produtiva a associação feita pelos alunos com outras doenças cotidianas em cuja denominação se emprega o sufixo -ite: otite, gastrite.

Como acima mencionamos, tais comentários eram feitos e provocados pela pesquisadora sem prejuízo da manutenção do chamado pacto ficcional, ou seja: da aceitação, pelos leitores, da história como uma história "real". Eco nos relembra a respeito:

A norma básica para se lidar com uma obra de ficção é a seguinte: o leitor precisa aceitar tacitamente um acordo ficcional, que Coleridge chamou de "suspensão da descrença". O leitor tem de saber que o que está sendo narrado é uma história imaginária, mas nem por isso deve pensar que o escritor está contando mentiras. (...) Aceitamos o acordo ficcional e fingimos que o que é narrado de fato aconteceu (ECO, 1994, p.81). 
Assim, os diálogos provocados pela leitura compartilhada, mediados pelo pesquisador, em nenhum momento resvalaram para a desconstrução da ficcionalidade ou questionamento da veracidade do enredo. Nesse sentido, especificamente em relação às turmas cujas manifestações vimos analisando, é possível que as experiências anteriores de leitura constante e regular no espaço escolar também tenham desempenhado seu papel.

Outro pressuposto do trabalho com a leitura compartilhada que assumimos na pesquisa diz respeito à possibilidade e à importância de instrumentalizar os novos leitores para a atenção a elementos editoriais do objeto livro, como elementos paratextuais: informações sobre autor, ilustrador, tradutor; contracapa, dedicatórias, edição etc., com o objetivo de levá-los à exploração de seu papel como veículo de informações que podem complementar a leitura do texto principal e não, simplesmente, como conhecimentos ou conteúdos escolarizados.

Duas observações se fazem necessárias sobre esse tópico. Em primeiro lugar, chamamos atenção para o fato de que, nos projetos gráficos mais recentes de literatura infantil, abundam os elementos paratextuais, possivelmente também com uma intenção mercadológica - possibilitar ao primeiro destinatário (frequentemente o adulto pai, mãe, professora) uma rápida identificação da temática do livro, do gênero, da sua adequação a objetivos de formação, de entretenimento, de aprendizagem. Dados complementares sobre edição e tradução, dedicatórias, (auto)biografias de autor e ilustrador, sinopse da obra na contracapa são elementos quase onipresentes nos livros que se publicam hoje, ao menos aqueles editados por editoras com mais tradição e/ou estrutura e que são, mormente, os que integram acervos oficiais.

A exploração de alguns desses elementos nas primeiras sessões de leitura conjunta rapidamente frutificou nas posturas de leitura dos alunos. Dessa forma, com presteza as crianças passaram a se dar conta do que era uma contracapa, dos elementos que ali frequentemente estavam presentes e, no caso específico de $A$ Grande Fábrica de Palavras, foi discutida a questão da tradução. Ao convite da pesquisadora para que olhassem a página seguinte à capa, alguns alunos leem, outros verbalizam as imagens, outros procuram descrevê-las melhor etc.:

P- Agora vamos a outra página.

A6- A contracapa.

A7 - Primeira edição!

A8 - Uma cereja.

A9 - Uma cadeira.

A4 - Um coração.

A5 - E palavras.

A1- Umas pegadas.

A2 - Um coração em volta da cadeira.

P- E bem embaixo ali do título do livro?

A6 - Autores e ilustradora.

$\mathrm{P}$ - E o que mais?

A6 - Tradução.

$\mathrm{P}-\mathrm{E}$ o que significa isso?

A6 - Que é de outro país.

A7 - Dos Estados Unidos.

A função das sinopses da contracapa foi logo captada por alguns alunos que, quando no início de uma sessão de leitura de um novo livro, se serviam dela para responderem a alguns desafios de predição do tema propostos pela pesquisadora. No caso de Controle Remoto trazemos dois exemplos, sendo que um dos alunos já demonstra mais familiaridade com os elementos paratextuais:

A12 - Este controle é para TV e este para o DVD, eu sei porque eu já li aqui (aponta a sinopse da contracapa)

P - Olha só, todo mundo abre bem no começo.

A1 - Tem dedicatória.

P- Para quem é a dedicatória?

A1 - Para Clessius e para Ana Paula.

Por fim, elencamos um último aspecto a ser destacado nos eventos de leitura, que diz respeito à fecundidade de sugestões de expansão dos significados da leitura através da proposta de atividades diferenciadas para os alunos a partir da especificidade de cada livro, como a criação de outros textos com um personagem da obra original mas com a sugestão de uma mudança temporal, por exemplo, ou a inversão de uma situação do texto primeiro, ou a produção de textos de outro gênero conectados a algum elemento do enredo (confecção de um anúncio publicitário de um produto citado no enredo, por exemplo) etc. 
Destacamos, assim, a importância de propiciar ao pequeno leitor uma apropriação mais livre e criativa de elementos do livro, que vá além de algumas atividades já bastante conhecidas e padronizadas, como "desenhar a cena que mais gostou, fazer fantoches ou bonecos dos personagens" ou, mesmo, para citar uma estratégia popularíssima nas atividades docentes, "mudar 0 final". Nesse sentido, Crinon, Marin e Lallias (2006), em obra sobre o ensino de literatura, subintitulam um de seus capítulos sobre a escrita com a afirmação "Agir sobre um texto auxilia a melhor compreendêlo"7. Situados dentro de uma tradição francesa que, secularmente, levava os alunos a escrever sobre qualquer texto lido, principalmente com um objetivo avaliativo, os autores sugerem várias atividades que, fugindo às tradições da cultura escolar, poderiam ser caracterizadas como "escritos de invenção" - mudar o ponto de vista, passar de um gênero a outro, atualizar um texto, por exemplo. $E$ eles observam que, propondo tais tarefas, "o professor favorece igualmente, a longo prazo, a apropriação de conhecimentos sobre o funcionamento dos textos" ( $p$. 118), como seria o conhecimento do que constitui o narrador, ponto de vista e mesmo de gênero textual.

Ainda que, no contexto brasileiro, haja uma certa resistência em pensar que a leitura literária possa ser objeto de uma abordagem pedagógica, para além da simples instalação de um gosto pela leitura, ao menos nos anos iniciais de escolaridade, é forçoso reconhecer que a identificação (mesmo sem terminologia) de alguns elementos da construção literária, através de sua manipulação em textos próprios das crianças, criados a partir de outros, pode levar a um enriquecimento progressivo da leitura das obras.

Nessa busca de escapar da dimensão meramente lúdica ou recreativa nas atividades pósleitura e buscando vinculá-las a um elemento específico da obra e ao repertório cultural dos alunos, solicitamos que os jovens leitores, a partir da leitura de Obax, imaginassem outras chuvas a que a protagonista pudesse ter assistido (ela tinha visto uma chuva de flores, relembramos), escrevendo e ilustrando suas ideias. Elementos de diversas ordens foram então utilizados, como (estão em itálico as frases escritas, mantida a grafia original, e a descrição breve dos desenhos vem entre parênteses):

Está chovendo ingresso de vários cantores Band para meninos de 7 anos, que é a idade de Obax (veem-se ingressos onde estão escritos nomes: Madona, Belo, Empreguetes, Gabi, Tiaguinho, Jonas Brode, On Directo...)

Começou a chover notas de todo valor, as que tem preço absurdo e as inúteis e quase todas não esistiam. Mas dinheiro é dinheiro! (veem-se notas em que estão escritas cifras de $0,100,165,500,1000,00001$, 999.999.999)

\section{Fechando o percurso}

Nesta breve apresentação de aspectos que nossa experiência investigativa com leitura e discussão literárias em sala de aula tem nos mostrado como possibilidades importantes (embora não únicas) a serem consideradas para um trabalho fecundo de mediação com leitura de livros de qualidade, algumas observações finais se fazem necessárias. Destacaríamos, nesse sentido, a importância de se lançar mão (como pesquisadoresprofessores-mediadores), de estratégias de manutenção de interesse e diálogo no espaço de sala de aula, que é difícil em turmas mais numerosas. Assim é que leituras interativas, em que é desejável e produtivo se manter um foco de leitura e discussão, certamente demandam do mediador uma especial sensibilidade para questões de ritmo do trabalho conjunto, o que pode, eventualmente, provocar um corte em algum tópico que talvez interessasse a algum(ns) aluno(s) em especial. Por outro lado, é evidente a necessidade de um planejamento detalhado e culturalmente informado, pelo mediador, através de uma leitura anterior - atenta e perspicaz do livro a ser trabalhado. Como Chambers (2007b, p. 86-87) nos alerta, ao falar sobre a leitura em voz alta para os alunos, sob o título "Tiempo para prepararse":

\footnotetext{
${ }^{7}$ Tradução das autoras.
} 
nunca les lea um cuento a los niños hasta que no lo haya leído usted mismo. Por qué? (...) muy pocas personas son tan buenas leyendo a primera vista como para hacerlo sin preparación, lo que significa más que uma lectura previa, em silencio, del texto.

De qualquer forma, é importante estar preparado e aberto para as dúvidas, leituras divergentes, hipóteses insuspeitas e comentários variados que as crianças fazem, no momento em que se sentem implicadas na leitura do livro e em um espaço não censurado de manifestação.

Por fim, é preciso pontuar que, no projeto do qual decorreu o presente trabalho, trabalhamos com a estratégia de cada aluno da sala ter um exemplar de um mesmo livro em mãos ${ }^{8}$, o que, sem dúvida, resultou num acréscimo de interesse e de riqueza de exploração conjunta. Detalhes difíceis de serem percebidos quando vistos a distância - no exemplar na mão do mediador - se tornam acessíveis ao leitor, além do inegável prazer do manuseio do objeto livro. Certamente, concordamos com Paiva (2012b), quando esboça uma espécie de diagnóstico sobre a possibilidade de encontro do leitor com o livro literário. Afirma a pesquisadora:

Três aspectos podem promover o encontro do leitor com o livro no contexto escolar: um ambiente físico, concebido como espaço de vivências de leitura e não apenas de guarda dos livros; um acervo literário bem selecionado e acessível ao toque do leitor e, por último, mas não menos importante nessa promessa de encontro, a figura do mediador, pois é preciso convencer o aluno de que esse encontro vale a pena (PAIVA, 2012b, 30-31).

Nesse sentido, a pesquisa empírica realizada pôde comprovar essa hipótese, uma vez que, durante as sessões de leitura, o acervo selecionado, a leitura prévia das obras por parte dos mediadores a fim de coordenar uma mediação produtiva de leitura, a preparação e planejamento dos encontros e o acesso dos leitores ao objeto livro, tornaram ricas e desafiadoras as sessões, contribuindo, acreditamos,

\footnotetext{
${ }^{8}$ Outra alternativa não tão eficiente, mas também produtiva e mais viável economicamente é que cada dupla de alunos tenha acesso a um exemplar, desde que a dupla de crianças se sente lado a lado.
}

para repercussões efetivas numa possível trajetória dos alunos na educação literária.

Por fim, vale relembrar a hipótese de Chambers (2007a, p. 35) de que uma experiência produtiva como a da discussão de obras pode resultar no reconhecimento gradual, pelos alunos, da importância social da leitura literária. E ele completa seu argumento, observando que as pessoas (e esperamos que, também, nossos pequenos leitores) "descubren de primera mano como la lectura (...) nos oferece imágenes para pensar y um médio para crear y recrear la esencia misma de nuestras vidas individuales y colectivas."

\section{Referências}

CHAMBERS, Aidan. Dime - los niños, la lectura y la conversación. Mexico: Fondo de Cultura Económica, 2007a.

El ambiente de la lectura. Mexico: Fondo de Cultura Económica, 2007b.

Conversaciones. Escritos sobre la literatura y los ninos. Mexico: Fondo de Cultura Económica, 2008.

COLOMER, Teresa. A formação do leitor literário. São Paulo: Global, 2003. 454p.

. Andar entre livros. São Paulo: Global, 2007. $207 p$.

CRINON, Jacques.; MARIN, Brigitte.; LALLIAS, JeanClaude. Enseigner la literature. Paris: Nathan, 2006. 238p.

DELAMOTTE-LEGRAND, Régine. O que as narrativas infantis nos ensinam sobre a narrativa e o restante. In: FRANÇOIS, Fréderic.; Crianças e narrativas. Maneiras de sentir, maneiras de dizer... São Paulo: Humanitas, 2009. 274p. p. 11-44.

ECO, Umberto. Seis passeios pelos bosques da ficção. São Paulo: Companhia das Letras, 1994. $160 p$.

PAIVA, Aparecida. (Org.) Literatura fora da caixa: o PNBE na escola: distribuição, circulação e leitura. São Paulo: Editora UNESP, 2012a. 216p.

PAIVA, Aparecida. Todo livro tem de estar onde o leitor está. In: ROSA, Cristina Maria (Org.). Escritas, leitores e história da leitura. Pelotas: Ed. UFPel, 2012b. 206p. p. 21-31 
ROCHE, Mary. Developing Children's Critical Thinking through Picturebooks. A guide for primary and early years students and teachers. New York: Routledge, 2014. 195p.

\section{COMO CITAR ESSE ARTIGO}

HESSEL SILVEIRA, Rosa Maria; FONSECA RICHTHOFEN DE FREITAS, Letícia. LIVROS LITERÁRIOS EM SALA DE AULA: POSSIBILIDADES DE LEITURA E CONVERSA LITERÁRIA. Signo, Santa Cruz do Sul, v. 43, n. $78, \quad$ nov. 2018. ISSN 1982-2014 <https://online.unisc.br/seer/index.php/signo/article/view/12165>. Acesso em: https://doi.org/10.17058/signo.v43i78.12165. 